\title{
Effect of Trichoderma isolates on primordia formation of crossbred cultures of Agaricus bisporus (Lange) Imbach
}

\author{
Wpływ izolatów Trichoderma na tworzenie zawiązków owocników \\ kultur krzyżówkowych Agaricus bisporus (Lange) Imbach
}

\author{
Romuald Górski ${ }^{1}$, Krzysztof Sobieralski ${ }^{2}$, Marek Siwulski ${ }^{2}$, Iwona Sas-Golak ${ }^{2}$, Daniel Lewandowski ${ }^{2}$
}

\section{Summary}

The aim of the studies was determination of Trichoderma effect on primordia formation of crossbred cultures of Agaricus bisporus. Isolates of two Trichoderma species originated from domestic mushroom farms, i.e. T. aggressivum f. europeaum and T. hamatum were used. The assessment of the primordia formation was carried out in glass cylinders of $600 \mathrm{~cm}^{3}$ volume and $10 \mathrm{~cm}$ diameter. It was found that both Trichoderma species influenced significantly the number of primordia formed by strains and crossbred cultures of $A$. bisporus. All the T. aggressivum f. europeaum isolates, i.e. T. 361, CBS115901 and T. agg. 29/15 drastically limited the primordia formation by Agaricus strains and crossbred cultures. It was demonstrated in the case of $T$. hamatum that isolate T. ham. 7/33 decreased the number of primordia to a much greater extent than the other two isolates T. ham.3/74 and T. ham. 9/11.

Key words: button mushroom; primordial; crossbred cultures; green moulds

\section{Streszczenie}

Celem badań było określenie wpływu różnych izolatów Trichoderma na wiązanie zawiązków owocników kilkunastu kultur krzyżówkowych Agaricus bisporus. Wykorzystano izolaty dwóch gatunków Trichoderma pochodzących z krajowych pieczarkarni: T. aggressivum f. europeaum oraz $T$. hamatum. Ocenę wiązania owocników przeprowadzono w cylindrach szklanych o pojemności $600 \mathrm{~cm}^{3}$ i średnicy $10 \mathrm{~cm}$. Wykazano bardzo duży wpływ izolatów obu gatunków Trichoderma na ilość zawiązków owocników wytworzonych przez badane odmiany i kultury krzyżówkowe pieczarki. Izolaty T. aggressivum f. europeaum: T. 361, CBS115901 oraz T. agg. 29/15 powodowały drastyczne ograniczenie wiązania owocników przez odmiany i kultury krzyżówkowe pieczarki. W przypadku T. hamatum wykazano, że izolat T. ham. $7 / 33 \mathrm{w}$ większym stopniu obniżał ilość wytworzonych zawiązków owocników niż dwa pozostałe izolaty T. ham. 3/74 oraz T. ham. 9/11.

Słowa kluczowe: pieczarka dwuzarodnikowa; zawiązki owocników; kultury krzyżówkowe; zielone pleśnie

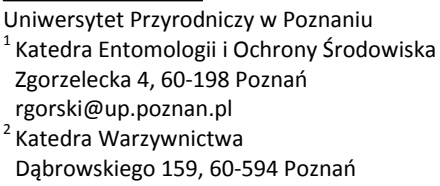




\section{Wstęp / Introduction}

Zielone pleśnie porażające uprawy pieczarek w wyniku występowania grzybów rodzaju Trichoderma są w ostatnich latach bardzo poważnym zagrożeniem (Kredics i wsp. 2010). Duże straty powodowane przez różne gatunki Trichoderma obserwowano w latach 1985-1986 w Wielkiej Brytanii oraz Irlandii (Seaby 1996). Infekcja upraw pieczarek zielonymi pleśniami szybko rozprzestrzeniała się, w 1994 roku obserwowano porażenie w Holandii (Geels 1997), a trzy lata później w Hiszpanii i Francji (Hermosa i wsp. 2000; Mamoun i wsp. 2000a). W ostatnich latach zidentyfikowano porażenie pieczarki grzybami rodzaju Trichoderma na Wegrzech (Hatvani i wsp. 2007), w Polsce (Szczech i wsp. 2008), a także Meksyku (Romero-Arenas i wsp. 2009), Australii (Clift i Shamshad 2009) oraz Chorwacji (Hatvani i wsp. 2012). Największe straty w uprawie pieczarki powoduje Trichoderma aggresivum f. europaeum (Szczech i wsp. 2008; Sobieralski i wsp. 2009b). Gatunek ten poraża grzybnię i owocniki (Hermosa i wsp. 2000; Samuels i wsp. 2002) oraz wpływa na obniżenie wielkości i jakości plonu pieczarki (Sharma i wsp. 1999; Mamoun i wsp. 2000b; Sobieralski i wsp. 2009a). Źródło zakażenia stanowi podłoże, okrywa lub grzybnia (Błażej i Tekiela 2002; Tekiela 2005; Sobieralski i wsp. 2009b).

W krajowych pieczarkarniach najczęściej izolowano gatunki: T. harzianum, T. atroviride, T. longibrachiatum oraz T. aggresivum (Szczech i wsp. 2008). Do gatunków o stosunkowo małej patogeniczności można zaliczyć: T. viride, T. aureoviride, T. pseudokoningii oraz T. hamatum (Seaby 1996; Fletcher i Gaze 2008). Szereg badań prowadzonych w różnych ośrodkach naukowych wykazało występowanie skomplikowanej interakcji pomiędzy Agaricus bisporus a grzybami rodzaju Trichoderma (Krupke i wsp. 2003; Savoie i Mata 2003; Williams i wsp. 2003; Largeteau i Savoie 2010).

Celem przeprowadzonych badań była ocena wpływu różnych izolatów grzybów rodzaju Trichoderma pochodzących z krajowych pieczarkarni na wiązanie zawiązków owocników kilkunastu kultur krzyżówkowych Agaricus bisporus.

\section{Materiały i metody / Materials and methods}

Doświadczenie przeprowadzone zostało w laboratorium biologicznym Katedry Warzywnictwa Uniwersytetu Przyrodniczego w Poznaniu. W doświadczeniu użyto kultur krzyżówkowych uzyskanych poprzez krzyżowanie kultur jednozarodnikowych różnych odmian pieczarki dwuzarodnikowej A. bisporus. Porównanie wzrostu grzybni kultur krzyżówkowych oraz odmian przeprowadzono na pożywce agarowej standardowej, pożywce obornikowej oraz w podłożu zastępczym według metody podanej przez Sobieralskiego (1998) w 3 powtórzeniach.

$\mathrm{W}$ badaniach wykorzystano izolaty dwóch gatunków Trichoderma: T. aggressivum f. europeaum oraz T. hamatum. Izolaty pochodziły z kolekcji grzybów Katedry Warzywnictwa Uniwersytetu Przyrodniczego w Poznaniu. Charakterystykę izolatów przedstawiono w tabeli 1 .

Ocenę wiązania owocników prowadzono w cylindrach szklanych o pojemności $600 \mathrm{~cm}^{3}$ i średnicy $10 \mathrm{~cm}$. Cylindry wypełniono do $2 / 3$ ich wysokości grzybnią na ziarnie pszenicy badanych kultur A. bisporus. Na górną powierzchnię grzybni pieczarki nałożono po 5 ziaren pszenicy przerośniętych strzępkami badanych izolatów Trichoderma, rozmieszczając je równomiernie na całej powierzchni. Następnie nałożono 6-centymetrową warstwę okrywy torfowej. Inkubację prowadzono w temperaturze $25^{\circ} \mathrm{C}$, przy wilgotności względnej powietrza 90-95\%, aż do wrośnięcia grzybni pieczarki w okrywę do wysokości $5,5 \mathrm{~cm}$. Po inkubacji temperaturę obniżono do $15^{\circ} \mathrm{C}$. $\mathrm{Na}$ powierzchni okrywy liczono zawiązki powstałe do 16. dnia od momentu obniżenia temperatury. Liczbę zawiązków przeliczano na $1 \mathrm{~cm}^{2}$ powierzchni. Kontrolę dla każdej odmiany i kultury krzyżówkowej stanowiła kombinacja nieinfekowana izolatami Trichoderma. Szczegółowy opis metody podał Sobieralski (1998).

Doświadczenie założono w układzie całkowicie losowym w 4 powtórzeniach i 2 seriach. Wyniki analizowano przy użyciu analizy wariancji dla doświadczeń czynnikowych przy poziomie istotności $\alpha=0,05$ (test NewmanaKeulsa). Wyniki omówiono na podstawie wartości średnich uzyskanych z 2 serii doświadczeń ze względu na brak statystycznie istotnych różnic pomiędzy seriami.

Tabela 1. Pochodzenie izolatów Trichoderma użytych do badań

Table 1. Derivation of Trichoderma isolates used in the experiments

\begin{tabular}{|c|c|c|}
\hline $\begin{array}{l}\text { Nr izolatu } \\
\text { No. of isolate }\end{array}$ & Gatunek - Species & Pochodzenie - Derivation \\
\hline T 361 & T. aggressivum f. europaeum & Viena University of Technology \\
\hline CBS 115901 & T. aggressivum f. europaeum & $\begin{array}{l}\text { The Centraalbureau voor Schimmelcultures } \\
\text { (CBS) Fungal Biodiversity Centre }\end{array}$ \\
\hline T. agg. 29/15 & T. aggressivum f. europaeum & Poznań \\
\hline T. ham. 3/74 & T. hamatum & Kościan \\
\hline T. ham. $7 / 33$ & T. hamatum & Skierniewice \\
\hline T. ham. 9/11 & T. hamatum & Poznań \\
\hline
\end{tabular}




\section{Wyniki i dyskusja / Results and discussion}

W tabeli 2. przedstawiono wzrost grzybni badanych odmian i kultur krzyżówkowych na pożywce agarowej standardowej i obornikowej oraz podłożu zastępczym. Wykazano bardzo duże zróżnicowanie wzrostu badanych odmian i kultur krzyżówkowych zarówno na pożywkach, jak i podłożu zastępczym. Średnica pożywki przerośniętej przez grzybnię na pożywce agarowej standardowej po okresie inkubacji wahała się od $16 \mathrm{~mm}$ (kultura krzyżówkowa KW./3/71) do $38 \mathrm{~mm}$ (odmiana Polmycel 23). Na pożywce obornikowej stwierdzono także bardzo duże zróżnicowanie wzrostu grzybni. Średnica pożywki przerośniętej przez grzybnię wahała się od $31 \mathrm{~mm}$ (kultura krzyżówkowa KW./11/24) do 86 mm (odmiana Somycel 91). Na podłożu zastępczym warstwa podłoża przerośnięta przez grzybnię wahała się od $41 \mathrm{~mm}$ (kultura krzyżówkowa KW./5/149) do $105 \mathrm{~mm}$ (kultura krzyżówkowa $\mathrm{KW} . / 8 / 67)$.

Wykazano bardzo duży wpływ izolatów T. aggressivum f. europaeum na tworzenie zawiązków owocników przez badane odmiany i kultury krzyżówkowe pieczarki (tab. 3). Wszystkie trzy izolaty: T. 361, CBS115901 oraz T. agg. 29/15 powodowały drastyczne ograniczenie wiązania owocników przez odmiany i kultury krzyżówkowe pieczarki $\left(0,2-1,0\right.$ szt./ $\left.\mathrm{cm}^{2}\right)$. W kilkunastu przypadkach odmiany i kultury krzyżówkowe na skutek infekcji nie wytworzyły żadnych zawiązków. Średnia liczba zawiązków wytworzonych przez badane odmiany i kultury krzyżówkowe zainfekowane w/w izolatami była bardzo zbliżona.

Uzyskane dane potwierdzają wcześniejsze wyniki badań autorów odnośnie dużej agresywności izolatów grzybów T. aggressivum f. europaeum, które powodowały znaczne zmniejszenie tworzenia zawiązków, a także bardzo znaczną obniżkę plonu (Sobieralski i wsp. 2010). Dużą agresywność izolatów $T$. aggressivum wykazali wcześniej m.in. Mamoun i wsp. (2000a), Savoie i wsp. (2001) oraz Samuels i wsp. (2002).

Izolaty $T$. hamatum wpływały także istotnie na tworzenie zawiązków owocników badanych odmian i kultur krzyżówkowych pieczarki. Średnia liczba zawiązków owocników wytworzonych przez odmiany i kultury krzyżówkowe zainfekowane izolatami $T$. hamatum wynosiła 0,8 oraz 1,0 szt. $/ \mathrm{cm}^{2}$ i była istotnie niższa od kontroli $\left(1,2 \mathrm{szt} . / \mathrm{cm}^{2}\right)$. Izolat T. ham. $7 / 33 \mathrm{w}$ większym stopniu obniżał ilość wytworzonych zawiązków owocników niż dwa pozostałe izolaty T. ham. 3/74 oraz T. ham. 9/11. Szereg autorów zalicza $T$. hamatum do grzybów nie wywierających dużego wpływu na plonowanie pieczarek (Seaby 1996; Fletcher i Gaze 2008). Uzyskane wyniki nie potwierdzają tych danych.

Tabela 2. Ocena wzrostu grzybni odmian i kultur krzyżówkowych uzyskanych poprzez krzyżowanie kultur jednozarodnikowych różnych odmian pieczarki dwuzarodnikowej $A$. bisporus

Table 2. Mycelium growth evaluation of strains and crossbred cultures obtained by crossing of $A$. bisporus single-spore cultures

\begin{tabular}{|c|c|c|c|c|}
\hline \multirow{2}{*}{$\begin{array}{l}\mathrm{Nr} \\
\text { No. }\end{array}$} & \multirow{2}{*}{$\begin{array}{l}\text { Odmiany i kultury krzyżówkowe } \\
\text { Strains and crosssbred cultures }\end{array}$} & \multicolumn{3}{|c|}{$\begin{array}{l}\text { Wzrost grzybni - Mycelium growth } \\
{[\mathrm{mm}]}\end{array}$} \\
\hline & & $\begin{array}{c}\text { pożywka agarowa } \\
\text { standardowa } \\
\text { standard agar medium }\end{array}$ & $\begin{array}{l}\text { pożywka obornikowa } \\
\text { manure medium }\end{array}$ & $\begin{array}{l}\text { podłoże zastępcze } \\
\text { substitute substrate }\end{array}$ \\
\hline 1. & Somycel 91 & $37 \mathrm{a}$ & $86 \mathrm{a}$ & $98 \mathrm{a}$ \\
\hline 2. & Hauser A6.5 & $35 \mathrm{a}$ & $80 \mathrm{a}$ & $102 \mathrm{a}$ \\
\hline 3. & KW./7/141 & $22 \mathrm{de}$ & $48 \mathrm{f}$ & $55 \mathrm{f}$ \\
\hline 4. & KW./9/76 & $25 \mathrm{c}$ & $55 \mathrm{e}$ & $62 \mathrm{e}$ \\
\hline 5. & KW./4/31 & $27 \mathrm{c}$ & $58 \mathrm{~d}$ & $81 \mathrm{c}$ \\
\hline 6. & KW./11/24 & $18 \mathrm{ef}$ & $31 \mathrm{~h}$ & $50 \mathrm{~g}$ \\
\hline 7. & KW./17/112 & $32 \mathrm{~b}$ & $67 \mathrm{c}$ & $93 \mathrm{~b}$ \\
\hline 8. & KW./8/67 & $34 \mathrm{ab}$ & $85 \mathrm{a}$ & $105 \mathrm{a}$ \\
\hline 9. & $\mathrm{KW} / 3 / 71$ & $16 \mathrm{f}$ & $32 \mathrm{~h}$ & $50 \mathrm{~g}$ \\
\hline 10. & Italspawn F62 & $32 \mathrm{~b}$ & $64 \mathrm{c}$ & $93 \mathrm{~b}$ \\
\hline 11. & Polmycel 23 & $38 \mathrm{a}$ & $61 \mathrm{~d}$ & $90 \mathrm{~b}$ \\
\hline 12. & KW./26/15 & $18 \mathrm{ef}$ & $40 \mathrm{~g}$ & $67 \mathrm{e}$ \\
\hline 13. & KW./18/43 & $33 \mathrm{~b}$ & $60 \mathrm{~d}$ & $75 \mathrm{~d}$ \\
\hline 14. & KW./31/17 & $34 \mathrm{ab}$ & $65 \mathrm{c}$ & $81 \mathrm{c}$ \\
\hline 15. & KW./5/149 & $18 \mathrm{ef}$ & $32 \mathrm{~h}$ & $41 \mathrm{~h}$ \\
\hline 16. & KW./2/110 & $36 \mathrm{a}$ & $75 \mathrm{~b}$ & $96 \mathrm{ab}$ \\
\hline 17. & KW./16/168 & $21 \mathrm{~d}$ & $44 \mathrm{f}$ & $68 \mathrm{e}$ \\
\hline 18. & KW./33/19 & $23 \mathrm{~d}$ & $52 \mathrm{e}$ & $72 \mathrm{~d}$ \\
\hline
\end{tabular}

Wartości w kolumnach oznaczone tą samą literą nie różnią się istotnie na poziomie $\alpha=0,05$

Values in columns marked with the same letter do not differ significantly at $\alpha=0.05$ 
Tabela 3. Wpływ izolatów Trichoderma na tworzenie zawiązków owocników odmian i kultur krzyżówkowych $A$. bisporus [szt./cm ${ }^{2}$ ] Table 3. Effect of Trichoderma isolates on primordia formation of A. bisporus strains and crossbred cultures [pcs $\left./ \mathrm{cm}^{2}\right]$

\begin{tabular}{|c|c|c|c|c|c|c|c|c|}
\hline \multirow{4}{*}{$\begin{array}{c}\text { Odmiany, } \\
\text { kultury } \\
\text { krzyżówkowe } \\
\text { Strains, crossbred } \\
\text { cultures }\end{array}$} & \multicolumn{6}{|c|}{$\begin{array}{c}\text { Gatunek } \\
\text { Species }\end{array}$} & \multirow{4}{*}{$\begin{array}{c}\text { Kontrola } \\
\text { Contol }\end{array}$} & \multirow{4}{*}{$\begin{array}{c}\text { Średnia } \\
\text { Mean }\end{array}$} \\
\hline & \multicolumn{3}{|c|}{ T. aggressivum f. europaeum } & \multicolumn{3}{|c|}{ T. hamatum } & & \\
\hline & \multicolumn{3}{|c|}{$\begin{array}{c}\text { nr izolatu } \\
\text { No. of isolate }\end{array}$} & \multicolumn{3}{|c|}{$\begin{array}{c}\text { nr izolatu } \\
\text { No. of isolate }\end{array}$} & & \\
\hline & T. 361 & CBS115901 & T. agg. $29 / 15$ & T. ham. 3/74 & T. ham. 7/33 & T. ham. 9/11 & & \\
\hline Somycel 91 & 0,4 & 0,2 & 0,4 & 1,4 & 1,2 & 1,6 & 1,6 & $1,0 \mathrm{ab}$ \\
\hline Hauser A6.5 & 0,2 & 0,2 & 0,6 & 0,8 & 0,6 & 1 & 1,1 & $0,6 \mathrm{~cd}$ \\
\hline KW./7/141 & 0 & 0 & 0 & 0,2 & 0,2 & 0,2 & 0,3 & $0,1 \mathrm{e}$ \\
\hline KW./9/76 & 0,2 & 0 & 0,2 & 0,6 & 0,4 & 0,7 & 0,7 & $0,4 \mathrm{~d}$ \\
\hline KW./4/31 & 0 & 0 & 0 & 0,8 & 0,2 & 0,4 & 0,8 & $0,3 \mathrm{de}$ \\
\hline KW./11/24 & 0,6 & 0,4 & 0,2 & 1 & 0,6 & 1 & 1,2 & $0,7 \mathrm{c}$ \\
\hline KW./17/112 & 0,2 & 0,2 & 0,4 & 0,6 & 0,6 & 0,6 & 0,8 & $0,5 \mathrm{~cd}$ \\
\hline KW./8/67 & 0,4 & 0,2 & 0,6 & 1,8 & 1,4 & 1,8 & 2 & $1,2 \mathrm{a}$ \\
\hline KW./3/71 & 0,2 & 0,6 & 0,8 & 1,2 & 1,2 & 1,4 & 1,4 & $1,0 \mathrm{ab}$ \\
\hline Italspawn F62 & 0,4 & 0,2 & 0,4 & 2 & 1,8 & 2 & 2,2 & $1,3 \mathrm{a}$ \\
\hline Polmycel 23 & 0,6 & 0,8 & 0,6 & 1,6 & 1,4 & 1,8 & 2 & $1,3 \mathrm{a}$ \\
\hline KW./26/15 & 1 & 0,6 & 0,8 & 1,4 & 1,2 & 1,4 & 1,8 & $1,2 \mathrm{a}$ \\
\hline KW./18/43 & 0 & 0 & 0 & 0,2 & 0 & 0,2 & 0,2 & $0,1 \mathrm{e}$ \\
\hline KW./31/17 & 0 & 0,2 & 0 & 0,8 & 0,2 & 0,6 & 0,8 & $0,4 \mathrm{~d}$ \\
\hline KW./5/149 & 0 & 0 & 0 & 0,2 & 0 & 0 & 0,2 & $0,1 \mathrm{e}$ \\
\hline KW./2/110 & 0,6 & 0,8 & 0,4 & 1 & 1 & 0,8 & 1,1 & $0,8 \mathrm{bc}$ \\
\hline KW./16/168 & 0,2 & 0,4 & 0,4 & 1,2 & 1,4 & 1,2 & 1,5 & $0,9 \mathrm{~b}$ \\
\hline KW./33/19 & 0,8 & 0,8 & 0,6 & 1,6 & 1,5 & 1,4 & 1,7 & $1,2 \mathrm{a}$ \\
\hline Średnia - Mean & $0,3 \mathrm{~d}$ & $0,3 \mathrm{~d}$ & $0,4 \mathrm{~d}$ & $1,0 \mathrm{~b}$ & $0,8 \mathrm{c}$ & $1,0 \mathrm{~b}$ & $1,2 \mathrm{a}$ & \\
\hline
\end{tabular}

Wartości średnie oznaczone tą samą literą nie różnią się istotnie na poziomie $\alpha=0,05$

Means marked with the same letter do not differ significantly at $\alpha=0.05$

\section{Wnioski / Conclusions}

1. Izolaty grzybów T. aggressivum f. europaeum oraz T. hamatum zmniejszały istotnie liczbę wytworzonych zawiązków owocników przez badane odmiany oraz kultury krzyżówkowe pieczarki.

2. Izolaty $T$. hamatum $\mathrm{w}$ różnym stopniu ograniczały tworzenie zawiązków owocników przez badane odmiany i kultury krzyżówkowe.
Część badawcza pracy została sfinansowana ze środków na naukę w latach 2009-2012 jako projekt badawczy nr NN310 089037.

\section{Literatura / References}

Błażej J., Tekiela A. 2002. Występowanie grzybów pasożytniczych i konkurencyjnych dla pieczarki [Agaricus bisporus (Lange) Sing] w różnych podłożach i okrywie. Acta Sci. Pol. Hort. Cult. 1 (2): 33-41.

Clift A.D., Shamshad A. 2009. Modeling mites, moulds and mushroom yields in the Australian Mushroom Industry p. 491-497. In: Proc. 18th World IMACS/MODSIM 09 Congress (R.S. Anderssen, R.D. Braddock, L.T.H. Newham, eds). Cairns, Australia, IMACS/MODSIM, 3537 pp.

Fletcher J.T., Gaze R.H. 2008. Mushroom Pest and Disease Control. Manson Publishing Ltd, London, 192 pp.

Geels F.P. 1997. Rondetafel - bijeenkomst over Trichoderma. Champignoncultuur 41, p.13.

Hatvani L., Antal Z., Manczinger L., Szekeres A., Druzhinina I.S., Kubicek C.P., Nagy A., Nagy E., Vágvölgyi C., Kredics L. 2007. Green mold diseases of Agaricus and Pleurotus spp. are caused by related but phylogenetically different Trichoderma species. Phytopathology 97: 532-537.

Hatvani L., Sabolić P., Koscubé S., Kredics L., Vágvölgyi C., Kaliterna J., Ivić D., Dermić E., Kosalec I. 2012. The first report on mushroom green mould in Croatia. Arch. Ind. Hyg. Toxicol. 63: 481-487. 
Hermosa M.R., Grondona I., Iturriaga E.A., Diaz-Minguez J.M., Castro C., Monte E., Garcia-Acha I. 2000. Molecular characterization and identification of biocontrol isolates of Trichoderma. Appl. Environ. Microbiol. 66: 1890-1898.

Kredics L., Garcia Jimenez L., Naeimi S., Czifra D., Urban P., Manczinger L., Vágvölgyi C., Hatvani L. 2010. A challenge to mushroom growers, the green mould disease of cultivated champignons. In: Curr. Res., Technol. Edu. Topics Appl. Microbiol. Microbial Biotechnol. (A. Mendez-Vilas, ed.). Microbiology Book Series 2 (1), Formatex, Badajoz, Spain: 295-305.

Krupke O.A., Castle A.J., Rinker D.L. 2003. The North American mushroom competitor, Trichoderma aggressivum f. aggressivum, produces antifungal compounds in mushroom compost that inhibit mycelial growth of the commercial mushroom Agaricus bisporus. Mycol. Res. 107 (12): 1467-1475.

Largeteau M.L., Savoie J.M. 2010. Microbially induced diseases of Agaricus bisporus, biochemical mechanisms and impact on commercial mushroom production. Appl. Microbiol. Biotechnol. 86: 63-73.

Mamoun M., Savoie J.M., Olivier J.M. 2000a. Interaction between the pathogen Trichoderma harzianum Th2 and Agaricus bisporus in mushroom compost. Mycologia 92: 233-240.

Mamoun M., Iapicco R., Savoie J.M., Olivier J.M. 2000b. Green mould disease in France, Trichoderma harzianum Th2 and other species causing damage on mushroom farms. Mushroom Sci. 15: 625-632.

Romero-Arenas O., Lara M.H., Huato M.A.D., Hernandez F.D., Victoria D.A.A. 2009. The characteristics of Trichoderma harzianum as a limiting agent in edible mushrooms. Revista Colombiana de Biotecnologia 11: 143-151.

Samuels G.J., Dodd S.L., Gams W., Castelbury L.A., Petrini O. 2002. Trichoderma species associated with the green mold epidemic of commercially grown Agaricus bisporus. Mycologia 94 (1): 146-170.

Savoie J.M., Mata G. 2003. Trichoderma harzianum metabolites pre-adapt mushrooms to Trichoderma aggressivum antagonism. Mycologia 95 (2): 191-199.

Seaby D.A. 1996. Differentiation of Trichoderma taxa associated with mushroom production. Plant Pathol. 45: 905-912.

Sharma H.S.S., Kilpatrick M., Ward F., Lyons G., Burns L. 1999. Colonisation of phase II compost by biotypes of Trichoderma harzianum and their effect on mushroom yield and quality. Appl. Microbiol. Biotechnol. 51: 572-578.

Sobieralski K. 1998. Selekcja, ocena i krzyżowanie wybranych kultur jenozarodnikowych pieczarki dwuzarodnikowej Agaricus bisporus (Lange) Sing. Rocz. AR Poznań, Rozpr. Nauk., Zeszyt 291, 57 ss.

Sobieralski K., Siwulski M., Frużyńska-Jóźwiak D., Górski R. 2009a. Impact of Trichoderma aggressivum f. europaeum Th2 on the yielding of Agaricus bisporus. Phytopathologia 53: 5-10.

Sobieralski K., Siwulski M., Górski R., Frużyńska-Jóźwiak D. 2009b. Porównanie rozwoju grzybni grzybów z rodzaju Trichoderma pochodzacych z krajowych pieczarkarni. [Comparison of mycelium growth of Trichoderma genus fungi obtained from polish mushroom houses]. Prog. Plant Prot./Post. Ochr. Roślin 49 (2): 723-726.

Sobieralski K., Siwulski M., Frużyńska-Jóźwiak D. Górski R. 2010. Impact of infection with Trichoderma aggressivum f. europaeum isolates on carpophore setting and yielding of Agaricus bisporus. Phytopathologia 55: 35-41.

Szczech M., Staniaszek M., Habdas H., Uliński Z., Szymański J. 2008. Trichoderma spp. - the cause of green mold on polish mushroom farms. Veg. Crops Res. Bull. 69: 105-114.

Tekiela A. 2005. Grzyby patogeniczne w uprawie pieczarki dwuzarodnikowej Agaricus bisporus (Lange) Imbach. Acta Agrobot. 58 (2): 189-196.

Williams J., Clarkson J.M., Mills P.R., Cooper R.M. 2003. Saprotrophic and mycoparasitic components of aggressiveness of Trichoderma harzianum groups toward the commercial mushroom Agaricus bisporus. Appl. Environ. Microbiol. 69 (7): 4192-4199. 